\title{
Structural and Dielectric Properties of Sn Doped Barium Magnesuim Zirconium Titanate Perovskite Ceramics
}

\author{
Sankararao Gattu1 ${ }^{1}$, Kamala Sujani Dasari'2, Venkata Ramesh Kocharlakota ${ }^{3 *}$ \\ ${ }^{1}$ Department of Physics, MVJ College of Engineering, Near ITPB, Bangalore, India \\ ${ }^{2}$ Department of Physics, A. C. College, Guntur, India \\ ${ }^{3}$ Deptartment of Physics, GITAM Institute of Science, GITAM University, Visakhapatnam, India \\ Email: ${ }^{*}$ kvramesh11@gmail.com
}

Received 12 August 2015; accepted 27 November 2015; published 30 November 2015

Copyright (C) 2015 by authors and Scientific Research Publishing Inc.

This work is licensed under the Creative Commons Attribution International License (CC BY).

http://creativecommons.org/licenses/by/4.0/

(c) (i) Open Access

\section{Abstract}

Perovskite type ceramics $\left(\mathrm{Ba}_{0.9} \mathrm{Mg}_{0.1}\right)\left(\mathrm{Sn}_{\mathrm{x}} \mathrm{Zr}_{0.4-\mathrm{x}} \mathrm{Ti}_{0.6}\right) \mathrm{O}_{3}$ (with $\mathrm{x}=0.01,0.02,0.03$ and 0.04 ) relaxor composition prepared through solid state reaction route and calcinated at temperature is $1150^{\circ} \mathrm{C}$ for 5 hrs with intermediate mixing. The room temperature XRD study suggests that all the samples have the single phase cubic symmetry with space group pm $3 \mathrm{~m}$. The pellets were sintered at $1^{1500} \mathrm{C}$ for $4 \mathrm{hrs}$. Scanning Electron Microscope (SEM) observations revealed enhanced micro structural uniformity and retarded grain growth with decreasing Sn content. The dielectric measurements at constant frequency show that dielectric constant increases with Sn content. Loss factor and dielectric constant decreased with increasing frequency but at very high frequencies it was independent.

\section{Keywords}

Sn Doped, Barium Titanate, Dielectric Properties, Perovskite, Lead Free Ceramics

\section{Introduction}

Barium Titanate (BT) is the most common ferro electric material, which is used to manufacture electronic components such as multilayer capacitors, positive temperature coefficient thermistors, piezo electric transdures, and ferro electric memory, because of its excellent dielectric, piezo electric and ferro electric properties [1] [2].

${ }^{*}$ Corresponding author.

How to cite this paper: Gattu, S., Dasari, K.S. and Kocharlakota, V.R. (2015) Structural and Dielectric Properties of Sn Doped Barium Magnesuim Zirconium Titanate Perovskite Ceramics. World Journal of Condensed Matter Physics, 5, 346-352.

http://dx.doi.org/10.4236/wjcmp.2015.54035 
$\mathrm{Pb}(\mathrm{Zr}, \mathrm{Ti}) \mathrm{O}_{3}$, PZT based ceramics has been study more than anyone else ferroelectric because of their excellent dielectric properties [3]. However, the presence of lead in those materials is about $60 \%$ in weight [4], reconsidering its use in technical applications, due to its high toxicity of lead for the environment as well as for humans [5]-[9]. The micro structure and dielectric properties of BT can be modified by addition of the dopants such as $\mathrm{La}^{3+}, \mathrm{Ce}^{2+}, \mathrm{Mn}^{4+}, \mathrm{Nb}^{5+}, \mathrm{Nd}^{3+}, \mathrm{Cr}^{3+}, \mathrm{Zr}^{4+}, \mathrm{Mg}^{2+}, \mathrm{Sr}^{2+}$ and $\mathrm{Si}^{4+}$ to occupy $\mathrm{Ba}^{2+}$ on A sites or $\mathrm{Ti}^{4+}$ on $\mathrm{B}$ sites to form the solid solution [10]-[26]. It has been reported that [27] with $\sim 15 \% \mathrm{Zr}$ substitution in $\mathrm{Ba}(\mathrm{ZrTi}) \mathrm{O}_{3}$ the three transitions (rhombohedra to orthorhombic, orthorhombic to tetragonal and tetragonal to cubic) of BT, come towards the room temperature with enhanced dielectric constant. Further increase in $\mathrm{Zr}$ content beyond 15\%, a diffuse dielectric anomaly in ceramic has been observed with the decrease in transition temperature [28] and the material showed typical relaxor like behavior in the range $25 \%-42 \% \mathrm{Zr}$ substitution [29]. Unexpectedly the lead free ceramics show the relaxor properties at low temperatures [30]. Several attempts have been made by researchers on these materials to shift the $T_{c}$ to close to room temperature. It is well known that homovalent and hetrovalent substitution for barium and titanium ions gives rise to various behaviors including the shifting of the transition temperature. A small content of Ba replaced by Mg in BZT solid solution the dielectric peaks has been shifted. But the transition temperature shifted towards lower temperature. The $\mathrm{Sn}$ ion is smaller than the $\mathrm{Zr}$ ion. If we substitute the $\mathrm{Sn}$ in $\mathrm{Zr}^{+}$ion site the $\mathrm{T}_{\mathrm{c}}$ may be increased to room temperature and $\mathrm{Sn}^{4+}$ substituted BZT ceramic exhibits both high piezoelectric properties and good temperature stabilities in common usage temperature range. This inspired to work on effect of $\mathrm{Sn}$ on structural and dielectrical properties of $\left(\mathrm{Ba}_{0.9} \mathrm{Mg}_{0.1}\right)\left(\mathrm{Sn}_{\mathrm{x}} \mathrm{Zr}_{0.4-\mathrm{x}} \mathrm{Ti}_{0.6}\right) \mathrm{O}_{3}$ relaxor composition prepared through solid state reaction route.

\section{Experimental}

The perovskite samples of pure and Sn doped Barium Magnesium Zirconium Titanate (BMSZT (0.000), (0.010), (0.015), (0.020), (0.025)) were prepared by conventional solid state reaction method. The starting raw materials were $\mathrm{BaCO}_{3}$ (Chen Chems., Chennai), $\mathrm{TiO}_{2}$ (Loba Chem., Mumbai) and $\mathrm{ZrO}_{2}$ (Loba Chem., Mumbai), MgO (Chen Chems., Chennai) and $\mathrm{SnO}_{2}$ (E. Merck India Ltd.). All the powders were having more than $99 \%$ purity. The powders were taken in a suitable stachiometry for 20 gm of samples. The powders were thoroughly mixed in an agate mortar in dry and wet mixing with appropriate amount of Acetone for 6 hrs. After proper mixing, mixed powders were calcinated at $1150^{\circ} \mathrm{C}$ for $5 \mathrm{hrs}$. and a small amount polyvinyl alcohol was added to the calcinated powder for fabrication of pellets, which was burnt out during high temperature sintering. The circular disc shaped pellets were prepared by applying a uniaxial pressure of $4.5 \times 10^{6} \mathrm{~N} / \mathrm{m}^{2}$. The pellets were subsequently sintered at an optimized temperature of $1500^{\circ} \mathrm{C}$ for $4 \mathrm{hrs}$. A preliminary study on compound formation and structural parameters was carried out using an X-ray diffraction (XRD) technique with an X-ray powder diffractometer. The XRD pattern of the calcinated powder was recorded at room temperature PANAlytical X'pert pro with $\mathrm{CuK}_{a}$ radiation (1.5405 $\AA$ ) in a wide range of Bragg's angles $2 \theta\left(15 \leq 2 \theta \leq 80^{\circ}\right)$. Micro structures of sintered pellets were recorded by scanning electron microscope (SEM)(JEOM JSM-6380 LA). The pellets were then electrode with high purity air-drying silver paste and then dried at $500^{\circ} \mathrm{C}$ for $1 \mathrm{hr}$. Impedance spectroscopic analysis was done using a Agilent E4980A Precision LCR meter with temperature (150 - $330 \mathrm{~K})$ and frequency $(20 \mathrm{~Hz}-200 \mathrm{KHz})$.

\section{Results and Discussion}

\subsection{Structural Analysis}

Figure 1 shows the XRD pattern of the pure and Cu doped BMSZT (0.000, 0.010, 0.015, 0.020, 0.025) samples. The XRD analysis provides that the samples are having single perovskite structure. $\mathrm{BaTiO}_{3}(\mathrm{BT})$ has the tetragonal structure at room temperature. The ionic radii of $\mathrm{Ba}^{2+}$ and $\mathrm{Ti}^{4+}$ are $1.35 \AA$ and $0.605 \AA$ respectively. If we doped BTO with $\mathrm{Mg}^{2+}$ and $\mathrm{Zr}^{4+}$ whose ionic radii are both $0.72 \AA \mathrm{Mg}$ occupies A site and $\mathrm{Zr}$ occupies B site of BT.

The pure BMSZT single phased cubic structure when the Mg content is $<1.5 \%$ at $-\%$ [31] and $\mathrm{Zr}$ content is $<$ $0.42 \%$ at $-\%$ [32]. The small amount of Sn has ionic radius $0.69 \AA$ doping to BMSZT. By doping with Sn the diffraction angles are shifted towards the higher angle side indicating the decrease in lattice parameters due to the incorporation of smaller content of Sn in place of Zr. 


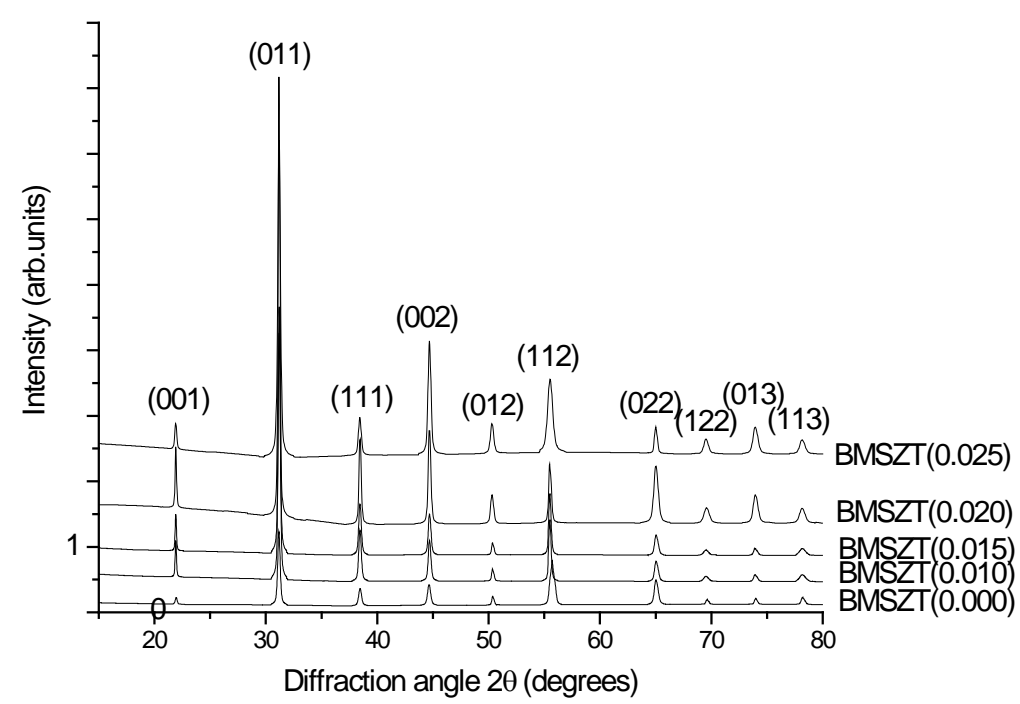

Figure 1. X-ray diffractograms of Sn doped BMSZT $(0.000,0.010,0.015$, $0.020,0.025)$ samples.

\subsection{Microstructural Analysis}

Figure 2 shows The SEM micrographs of pure and Sn dope BMSZT (0.000, 0.010, 0.015, 0.020, 0.025) samples. It is found that the average grain size of samples are $\sim 1.66, \sim 1.55, \sim 1.42, \sim 1.27$ and $\sim 1.25 \mu \mathrm{m}$ as the Sn content decreases from $0 \%$ to $0.025 \%$. This decrease is in agreement with our XRD pattern. Moreover the surface observation shows a good density of grains with some porosity.

\subsection{Dielectric Properties}

\subsubsection{Temperature Dependence Dielectric Properties}

Figure 3 shows the temperature dependence of the dielectric constant and loss of pure and Sn doped BMSZT samples measured at $1 \mathrm{MHz}$. The figure shows, the value of dielectric constant increases gradually to a maximum value $\left(\varepsilon_{m}\right)$ with increase in temperature up to transition temperature and then decreases indicating a phase transition. It is also found that the Curie temperature Tc of BMSZT samples with Sn dopant of $(0.000,0.010$, $0.015,0.020,0.025)$ corresponding to the maximum dielectric constant is 180, 200, 210, 225 and 250 respectively. The results indicates that the curie temperature of BMSZT increased may be due to $\mathrm{Zr}$ ions replaced by $\mathrm{Sn}$ ions and Sn ionic radius is some small, it can decrease the grain size, again decrease in curie temperature is may be due to occupying the more number of $\mathrm{Sn}$ atoms in $\mathrm{Zr}$ sites, due to the $\mathrm{Sn}$ ions conducts the little current then the dielectric constant may be decreased and curie temperature increased.

According to Figure 3(a) the peak value of the dielectric constant of BMSZT samples with the Sn dopant of $(0.000,0.010,0.015,0.020,0.025)$ is $566,551,510,480$ and 462 respectively. The result indicates that the peak value of dielectric constant for undoped sample is the maximum and the peak value decreases with Sn content.

Figure 3(b) shows that the dielectric loss initially increases with temperature reaches maximum. Further increase in temperature loss is decreased but for BMSZT sample of (0.020) it is at lower temperature high value of loss due to the presence of all types of polarisation and may be due to the contribution of finite resistivity of the materials. Further increase in temperature increase in ionic conductivity resulting from the disordering of mobile cations in the oxygen octahedral skeleton [32].

\subsubsection{Frequency Dependence Dielectric Properties}

As shown in Figure 4(a) first, it is found that the dielectric constant of BMSZT samples decreased with frequency. Second, it is also found the dielectric constant of BMSZT (0.015) decreased rapidly at low frequencies. At very high temperatures dielectric constant is very low and it maintains constant value. It may be due to there must be defects with opposite charges (dipoles) to preserve charge neutrality. Theses dipoles could be oriented to align the direction of the applied electric field. When the frequency increases, the dipoles do not catch up with 


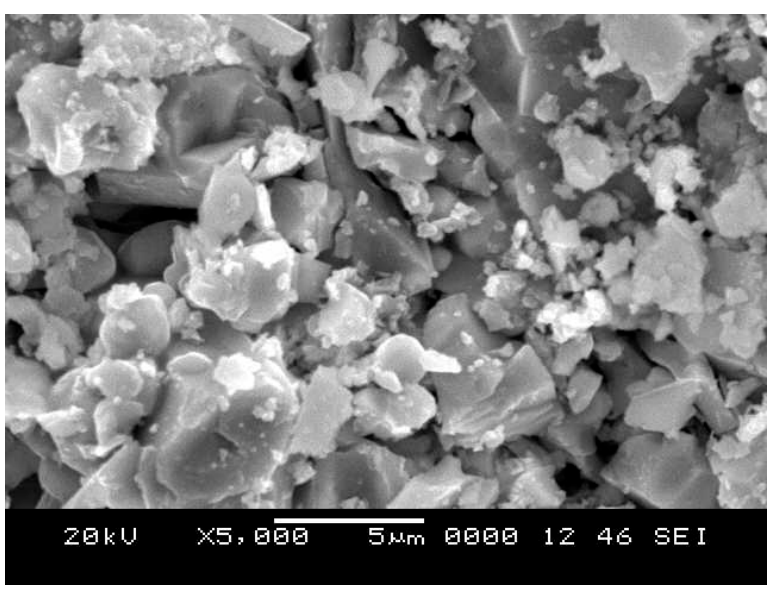

(a)

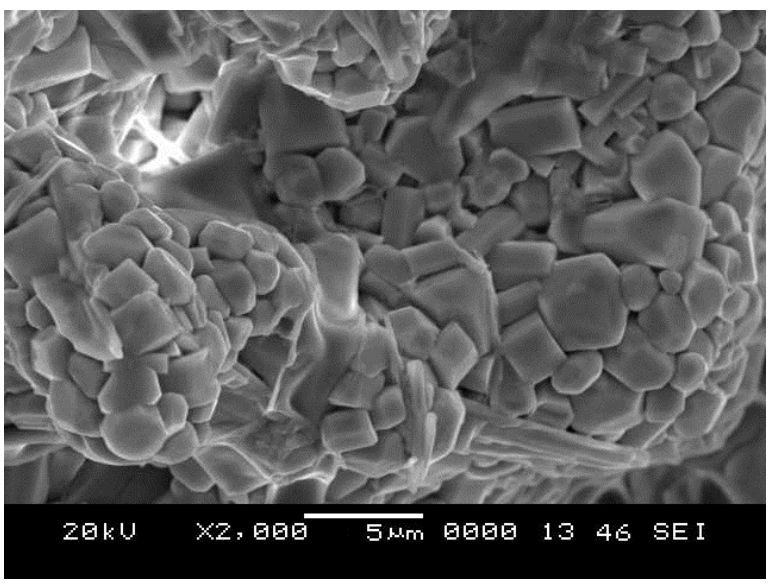

(c)

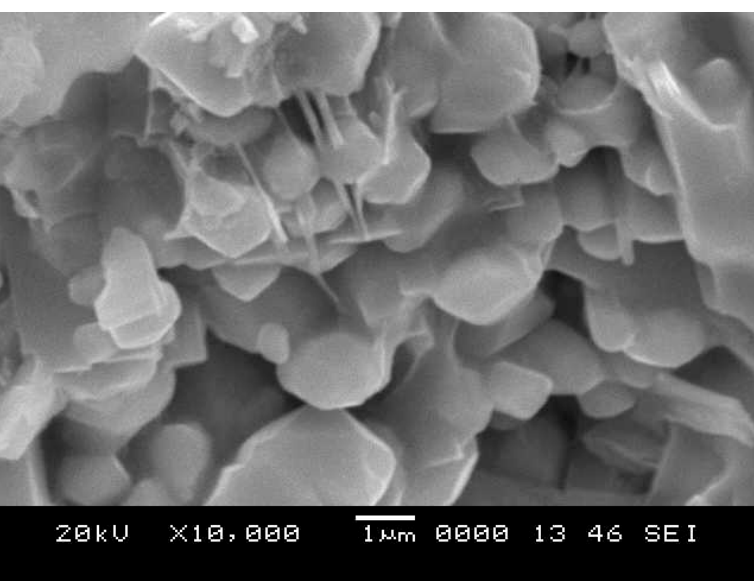

(b)

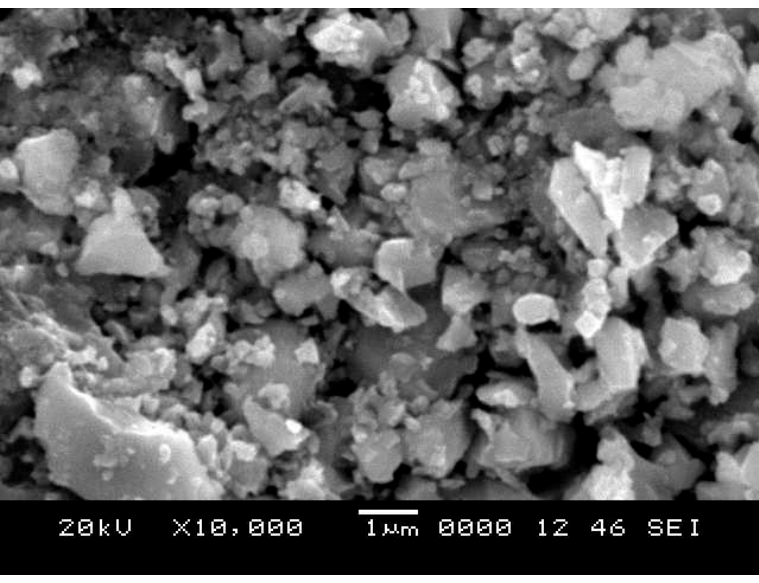

(d)

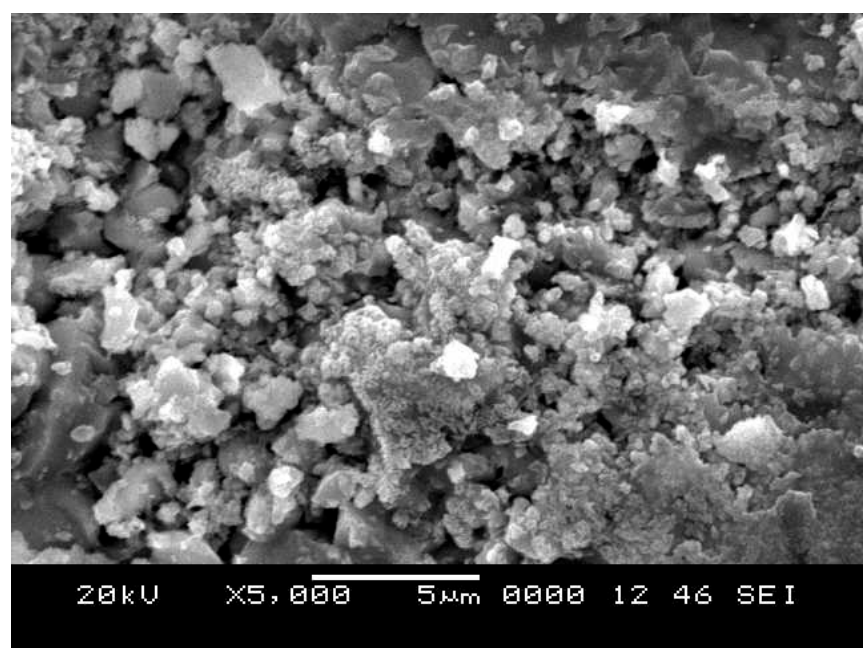

(e)

Figure 2. SEM micrograph of pure and Sn dope BMSZT ceramics. (a) 0.000; (b) 0.010; (c) 0.01; (d) 0.020; (e) 0.025.

the change of the electric field to complete polarisation so that the dielectric constant decreases.

In the Figure 4(b) the dielectric losses were a combined result of electrical conduction and orientational polarisation of the matter. The energy losses, which occur in dielectrics due to dc conductivity and dipole relaxation. The loss factor of a dielectric material is a useful indicator of the energy loss as heat. 


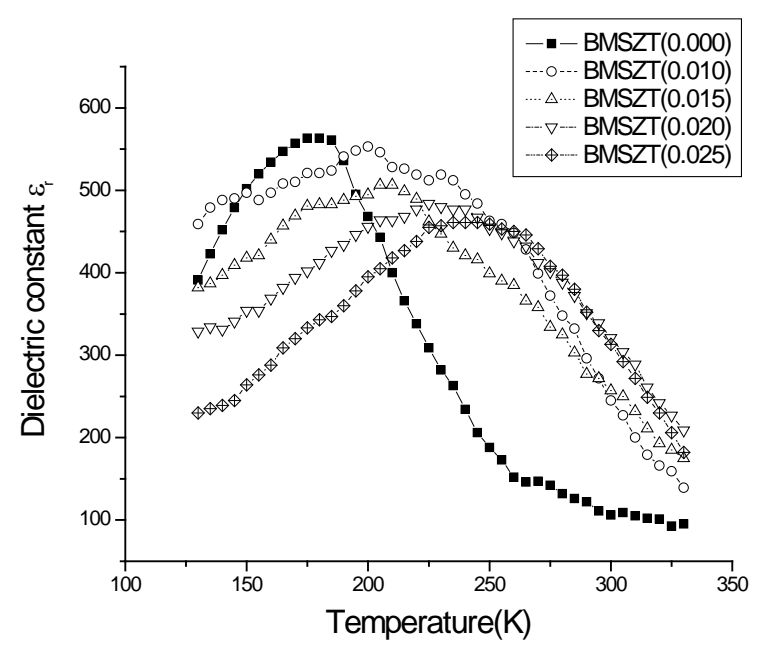

(a)

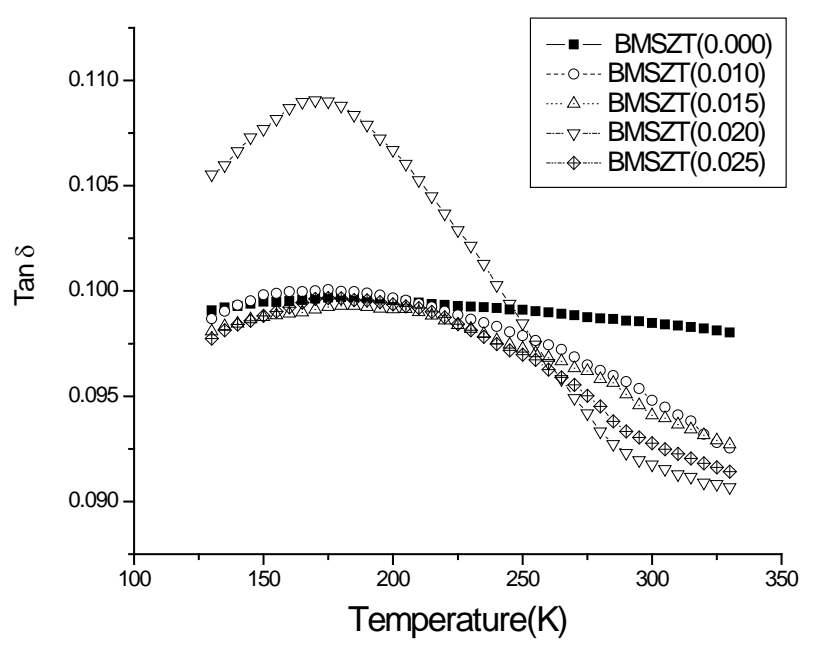

(b)

Figure 3. Temperature dependence of (a) Dielectric constant (b) Dielectric loss of pure and Sn dope BMSZT (0.000, 0.010, $0.015,0.020,0.025)$ samples.

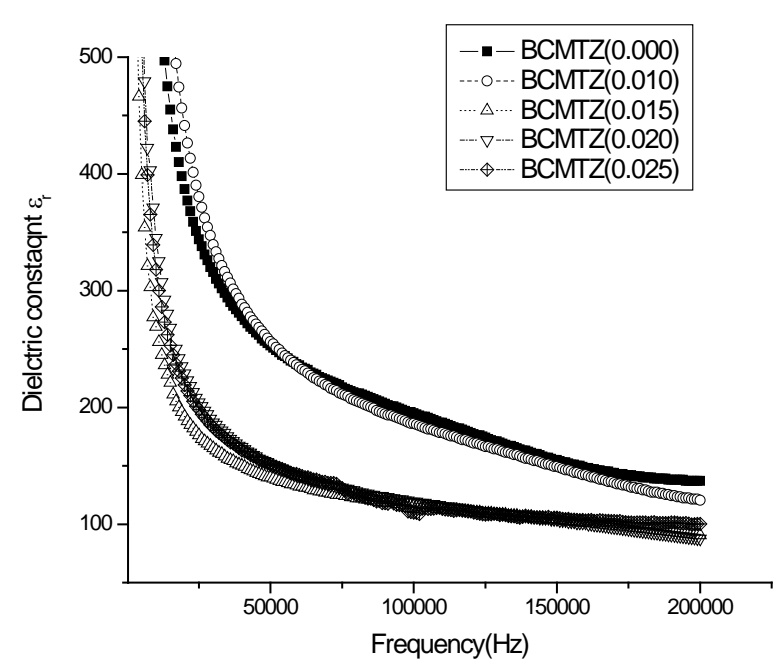

(a)

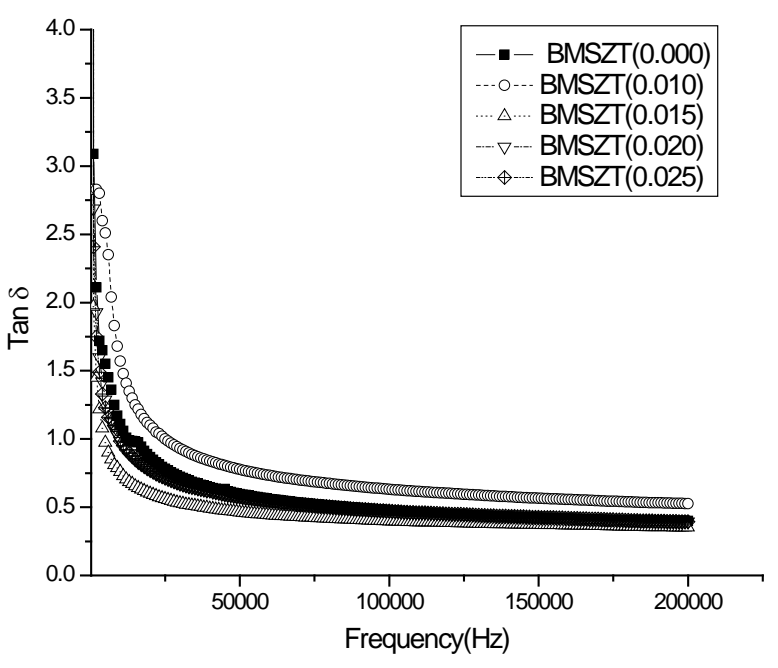

(b)

Figure 4. Frequency dependence of (a) Dielectric constant (b) Dielectric loss of Sn doped BMSZT (0.000, 0.010, 0.015, $0.020,0.025)$ samples.

\section{Conclusion}

Perovskite types $\left(\mathrm{Ba}_{0.9} \mathrm{Mg}_{0.1}\right)\left(\mathrm{Sn}_{\mathrm{x}} \mathrm{Zr}_{0.4-\mathrm{x}} \mathrm{Ti}_{0.6}\right) \mathrm{O}_{3}$ (with $\mathrm{x}=0.000,0.010,0.015,0.020,0.025$ ) ceramics have prepared through solid state reaction route. The room temperature XRD study suggests that the compositions have single phase cubic symmetry with space group pm-3m. The dielectric study reveals that the material undergoes a diffuse type ferroelectric phase transition. The transition temperature increased with Sn content and the dielectric constant decreased with Sn content.

\section{References}

[1] Mitic, V.V., Nikolic, Z.S., Pavlovic, V.B., Paunovic, V., Miljkovic, M., Jordovic, B. and Zivkovic, L. (2010) Influence of Rareearth Dopants on Barium Titanate Ceramics Microstructure and Corresponding Electrical Properties. Journal of the American Ceramic Society, 93, 132-137. http://dx.doi.org/10.1111/j.1551-2916.2009.03309.x

[2] Jung, W.S., Kim, J.H., Kim, H.T. and Yoon, D.H. (2010) Effect of Temperature Schedule on the Particle Size of Barium Titanate during Solid-State Reaction. Materials Letters, 64, 170-172. 
http://dx.doi.org/10.1016/j.matlet.2009.10.035

[3] Takenaka, T. and Nagata, H. (2005) Current Status and Prospects of Lead-Free Piezoelectric Ceramics. Journal of the European Ceramic Society, 25, 2693-2700. http://dx.doi.org/10.1016/j.jeurceramsoc.2005.03.125

[4] Saito, Y., Takao, H., Tani, T., et al. (2004) Lead-Free Piezoceramics. Lead-Free Piezoceramics. Nature, 432, 84-87. http://dx.doi.org/10.1038/nature03028

[5] Dixit, A., Majumder, S.B., Katiyar, R.S. and Bhalla, A.S. (2003) Relaxor Behavior in Sol-Gel-Derived $\mathrm{BaZr}_{(0.40)} \mathrm{Ti}_{(0.60)} \mathrm{O}_{3}$ Thin Films. Applied Physics Letters, 82, 2679-2681. http://dx.doi.org/10.1063/1.1568166

[6] Dobal, P.S., Katiyar, R.S. and Raman, J. (2002) Ferroelectric Perovskites and Bi-Layered Compounds Using MicroRaman Spectroscopy. Spectroscopy, 33, 405. http://dx.doi.org/10.1002/jrs.876

[7] Dixit, A., Majumder, S.B., Savvinov, A., Katiyar, R.S., Guo, R. and Bhalla, A.S. (2002) Investigations on the Sol-Gel-Derived Barium Zirconium Titanate Thin Films. Materials Letters, 56, 933-940. http://dx.doi.org/10.1016/S0167-577X(02)00640-7

[8] Paik, D.S., Park, S.E., Wada, S., Liu, S.F. and Shrout, T.R. (1999) E-Field Induced Phase Transition in <001>Oriented Rhombohedral 0.92Pb( $\left.\mathrm{Zn}_{1 / 3} \mathrm{Nb}_{2 / 3}\right) \mathrm{O}_{3}-0.08 \mathrm{PbTiO}_{3}$ Crystals. Journal of Applied Physics, 85, 1080. http://dx.doi.org/10.1063/1.369252

[9] Yu, Z., Ang, C., Guo, R. and Bhalla, A.S. (2002) Dielectric Properties and High Tunability of Ba(Ti $\left.{ }_{0.7} \mathrm{Zr}_{0.3}\right) \mathrm{O}_{3} \mathrm{Ceram-}$ ics under dc Electric Field. Applied Physics Letters, 81, 1285. http://dx.doi.org/10.1063/1.1498496

[10] Parkash, O., Kumar, D., Dwivedi, R.K., Srivastava, K.K., Singh, P. and Singh, S. (2007) Effect of Simultaneous Substitution of La and Mn on Dielectric Behavior of Barium Titanate Ceramic. Journal of Materials Science, 42, 54905496. http://dx.doi.org/10.1007/s10853-006-0985-8

[11] Langhammer, H.T., Müller, T., Böttcher, R. and Abicht, H.P. (2008) Structural and Optical Properties of ChromiumDoped Hexagonal Barium Titanate Ceramics. Journal of Physics: Condensed Matter, 20, Article ID: 085206. http://dx.doi.org/10.1088/0953-8984/20/8/085206

[12] Lu, D.Y., Toda, M. and Sugano, M. (2006) High-Permittivity Double Rare Earth-Doped Barium Titanate Ceramics with Diffuse Phase Transition. Journal of the American Ceramic Society, 89, 3112-3123. http://dx.doi.org/10.1111/j.1551-2916.2006.00893.x

[13] Chen, Z.W. and Chu, J.Q. (2008) Piezoelectric and Dielectric Properties of $\mathrm{Bi}_{0.5}\left(\mathrm{Na}_{0.84} \mathrm{~K}_{0.16}\right)_{0.5} \mathrm{TiO}_{3}-\mathrm{Ba}\left(\mathrm{Zr}_{0.04} \mathrm{Ti}_{0.96}\right) \mathrm{O}_{3}$ Lead Free Piezoelectric Ceramics. Advances in Applied Ceramics, 107, 222-226. http://dx.doi.org/10.1179/174367608X263403

[14] Fu, C.L., Cai, W., Chen, H.W., Feng, S.C., Pan, F.S. and Yang, C.R. (2008) Voltage Tunable $\mathrm{Ba}_{0.6} \mathrm{Sr}_{0.4} \mathrm{TiO}_{3} \mathrm{Thin}_{\mathrm{Films}}$ and Coplanar Phase Shifters. Thin Solid Films, 516, 5258-5261. http://dx.doi.org/10.1016/j.tsf.2007.07.059

[15] Cai, W., Fu, C.L., Gao, J.C. and Chen, H.Q. (2009) Effects of Grain Size on Domain Structure and Ferroelectric Properties of Barium Zirconate Titanate Ceramics. Journal of Alloys and Compounds, 480, 870-873. http://dx.doi.org/10.1016/j.jallcom.2009.02.049

[16] Du, F.T., Yu, P.F., Cui, B., Cheng, H.O. and Chang, Z.G. (2009) Preparation and Characterization of Monodisperse Ag Nanoparticles Doped Barium Titanate Ceramics. Journal of Alloys and Compounds, 478, 620-623. http://dx.doi.org/10.1016/j.jallcom.2008.11.099

[17] Yuan, Y., Zhang, S.R., Zhou, X.H. and Tang, B. (2009) Effects of $\mathrm{Nb}_{2} \mathrm{O}_{5}$ Doping on the Microstructure and the Dielectric Temperature Characteristics of Barium Titanate Ceramics. Journal of Materials Science, 44, 3751-3757. http://dx.doi.org/10.1007/s10853-009-3502-z

[18] Xiao, S.X. and Yan, X.P. (2009) Preparation and Characterization of Si-Doped Barium Titanate Nanopowders and Ceramics. Microelectronic Engineering, 86, 387-391. http://dx.doi.org/10.1016/j.mee.2008.11.042

[19] Rath, M.K., Pradhan, G.K., Pandey, B., Verma, H.C., Roul, B.K. and Anand, S. (2008) Synthesis, Characterization and Dielectric Properties of Europium-Doped Barium Titanate Nanopowders. Materials Letters, 62, 2136-2139. http://dx.doi.org/10.1016/j.matlet.2007.11.033

[20] Gulwade, D. and Gopalan, P. (2008) Diffuse Phase Transition in La and Ga Doped Barium Titanate. Solid State Communications, 146, 340-344. http://dx.doi.org/10.1016/j.ssc.2008.02.018

[21] Unruan, M., Sareein, T., Tangsritrakul, J., Prasetpalichatr, S., Ngamjarurojana, A., Anata, S. and Yimnirun, R. (2008) Changes in Dielectric and Ferroelectric Properties of $\mathrm{Fe}^{3+} / \mathrm{Nb}^{5+}$ Hybrid-Doped Barium Titanate Ceramics under Compressive Stress. Journal of Applied Physics, 104, Article ID: 124102. http://dx.doi.org/10.1063/1.3042228

[22] Yaseen, H., Baltianski, S. and Tsur, Y. (2006) Effect of Incorporating Method of Niobium on the Properties of Doped Barium Titanate Ceramics. Journal of the American Ceramic Society, 89, 1584-1589. http://dx.doi.org/10.1111/j.1551-2916.2006.00966.X

[23] Cha, S.H. and Han, Y.H. (2006) Effects of Mn Doping on Dielectric Properties of Mg-Doped BaTiO ${ }_{3}$. Journal of Ap- 
plied Physics, 100, Article ID: 104102. http://dx.doi.org/10.1063/1.2386924

[24] Shen, Z.J., Chen, W.P., Qi, J.Q., Wang, Y., Chan, H.L.W., Chen, Y. and Jiang, X.P. (2009) Dielectric Properties of

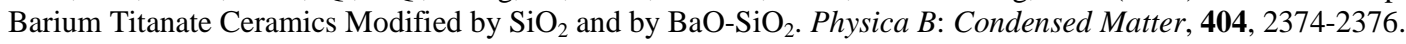
http://dx.doi.org/10.1016/j.physb.2009.04.039

[25] Kirianov, A., Hagiwara, T., Kishi, H. and Ohsato, H. (2002) Effect of Ho/Mg Ratio on Formation of Core-Shell Structure in $\mathrm{BaTiO}_{3}$ and on Dielectric Properties of $\mathrm{BaTiO}_{3}$ Ceramics. Japanese Journal of Applied Physics, 41, 6934-6937. http://dx.doi.org/10.1143/JJAP.41.6934

[26] Wang, S., Zhang, S.R., Zhou, X.H., Li, B. and Chen, Z. (2005) Effect of Sintering Atmospheres on the Microstructure and Dielectric Properties of $\mathrm{Yb} / \mathrm{Mg}$ Co-Doped $\mathrm{BaTiO}_{3}$ Ceramics. Materials Letters, 59, 2457-2460. http://dx.doi.org/10.1016/j.matlet.2005.03.016

[27] Henning, D., Schnell, A. and Simon, G. (1982) Diffuse Ferroelectric Phase Transitions in Ba(Ti $\left.\mathrm{Ti}_{1-\mathrm{y}} \mathrm{Zr}_{\mathrm{y}}\right) \mathrm{O}_{3} \mathrm{Ceramics}$ Journal of the American Ceramic Society, 65, 539-544. http://dx.doi.org/10.1111/j.1151-2916.1982.tb10778.x

[28] Yu, Z., Guo, R. and Bhalla, A.S. (2000) Dielectric Behavior of $\mathrm{Ba}\left(\mathrm{Ti}_{1-\mathrm{x}} \mathrm{Zr}_{\mathrm{x}}\right) \mathrm{O}_{3}$ Single Crystals. Journal of Applied Physics, 88, 410. http://dx.doi.org/10.1063/1.373674

[29] Yu, Z., Guo, R. and Bhalla, A.S. (2002) Dielectric Properties and High Tunability of $\mathrm{Ba}\left(\mathrm{Ti}_{0.7} \mathrm{Zr}_{0.3}\right) \mathrm{O}_{3}$ Ceramics under DC Electric Field. Applied Physics Letters, 81, 1285. http://dx.doi.org/10.1063/1.1498496

[30] Dixit, A., Majumder, S.B., Katiyar, R.S. and Bhalla, A.S. (2003) Relaxor Behavior in Sol-Gel-Derived $\mathrm{BaZr}_{(0.40)} \mathrm{Ti}_{(0.60)} \mathrm{O}_{3}$ Thin Films. Applied Physics Letters, 82, 2679. http://dx.doi.org/10.1063/1.1568166

[31] Cai, W., Fu, C.L., Gao, J.C. and Zhao, C.X. (2011) Dielectric Properties and Microstructure of Mg Doped Barium Titanate Ceramics. Advances in Applied Ceramics, 110, 181-185. http://dx.doi.org/10.1179/1743676110Y.0000000019

[32] Ravez, J. and Simon, A. (1997) Temperature and Frequency Dielectric Response of Ferroelectric Ceramics with Composition $\mathrm{Ba}\left(\mathrm{Ti}_{1-\mathrm{x}} \mathrm{Zr}_{\mathrm{x}}\right) \mathrm{O}_{3}$. European Journal of Solid State and Inorganic Chemistry, 34, 1199. 